Original Research Article

\title{
An evaluation of pattern of adverse drug reactions reporting by undergraduate medical students in a tertiary care hospital
}

\author{
Zorawar Singh Bali, Mohammad Younis Bhat*, Samina Farhat, Urfan Nabi
}

Department of Pharmacology, Govt. Medical College,

Srinagar, Jammu and Kashmir, India

Received: 08 January 2019

Revised: 14 February 2019

Accepted: 05 March 2019

\section{*Correspondence to:}

Dr. Mohammad Younis Bhat, Email: mohammad.younis50@ yahoo.com

Copyright: (C) the author(s), publisher and licensee Medip Academy. This is an openaccess article distributed under the terms of the Creative Commons Attribution NonCommercial License, which permits unrestricted noncommercial use, distribution, and reproduction in any medium, provided the original work is properly cited.

\begin{abstract}
Background: Adverse drug reactions (ADRs) are an important cause of mortality and morbidity worldwide and reporting ADRs voluntarily is fundamental to medical drug safety surveillance but gross underreporting of ADRs is a cause for a concern. Being key health care professional, physicians, pharmacists and nurses have immense responsibility in reporting of ADRs. Therefore, the sensitization and involvement of undergraduate medical students can reduce underreporting. This study is aimed at evaluating knowledge, attitude and reporting of quality of ADRs by undergraduate medical students.

Methods: The study was conducted after sensitizing the second professional year undergraduate students about Pharmacovigilance as part of their internal assessment and asked them to submit reports of ADR observed during their clinical posting.

Results: A total of 82 ADR's were reported after sensitization with majority of them i.e. 30 related to skin and appendages disorder followed by gastrointestinal tract with antibiotics i.e. 28 and analgesics being most common probable/possible culprits.

Conclusions: The response percentage of reporting ADRs was 54.66\%. Medical students being future healthcare professionals should be exposed to ADR reporting during their clinical teaching posting as a part of sensitization and make them actively involved in reporting to improve detection rate and make Pharmacovigilance a success.
\end{abstract}

Keywords: Adverse drug reaction, Pharmacovigilance, Sensitization, Undergraduate medical student

\section{INTRODUCTION}

The world health organization defines an adverse drug reaction as a response to a drug which is noxious, unintended and which occurs at doses normally used in man for the prophylaxis, diagnosis or therapy of disease or for modification of physiological function. ${ }^{1}$ ADRs are a global problem and one the leading causes of morbidity causing a substantial burden on health care resources. ${ }^{2}$ The incidence of serious ADRs is $6.7 \%$ in India and it has been reported that $2.4-6.5 \%$ of total admissions in the hospitals are due to adverse reactions, many of which are preventable. ${ }^{3,4}$ Monitoring of ADRs is carried out by various methods of which voluntary or spontaneous reporting is commonly practiced. Though, this system is inexpensive and easy to operate and encompasses all drugs and patient populations, including special groups but substantial underreporting and inability to calculate the incidence of ADRs are inherent disadvantages of this system which leads to long delays between marketing and detection/regulatory action of an adverse reaction. ${ }^{3,5}$ In one of the studies, $72 \%$ of surgical specialists and $81 \%$ of medical specialists had diagnosed an ADR but did not report due to multiple reasons. ${ }^{6}$

Physicians are the principal contributors of ADR reports to the spontaneous reporting system in India. Although physicians are aware of the ADRs and importance of their 
reporting, actual practice of ADR reporting is deficient. ${ }^{3,7}$ One method to reduce underreporting could be to expose them to the ADR reporting during their undergraduate study period which can cultivate ADR reporting habits and enhance their participation as a physician in future. Therefore, this study was planned with primary objective to evaluate the knowledge, attitude and practices towards Pharmacovigilance and adverse drug reactions and cultivate ADR reporting habits thereby enhancing their participation as a healthcare professional in future.

\section{METHODS}

This prospective, cross-sectional study was carried out in the Department of Pharmacology, Government Medical College, Srinagar (Jammu and Kashmir), a teaching postgraduate medical institute in North India after taking verbal oral consent and explaining the purpose of study among second professional undergraduate medical students. Reporting of ADRs by students was made a part of internal assessment in practicals in which the students were taught and sensitized about Pharmacovigilance through interactive theory and practical class teaching including terminologies relating to ADRs, types of ADRs and their management. The students were also given a hypothetical narrative for filling of ADR reporting form as a part of sensitization and building confidence in reporting of ADRs and were encouraged to collect and report ADRs during their two and a half hours posting in the morning in various clinical departments.

The ADR reporting form designed by CDSCO, India was used which has elements such as patient related information, suspected ADR and medications, dechallenge, rechallenge, concomitant medications, relevant laboratory test, seriousness, outcome and reporter's details. Our institution has a registered regional Pharmacovigilance centre in which we concentrate on spontaneous reporting of ADRs by clinicians, postgraduates and faculty members. The collected ADRs were transmitted to the "Vigiflow software' of the W.H.O for global monitoring of ADRs provided by Indian Pharmacopoeia Commission (IPC), Ghaziabad, India.

\section{RESULTS}

Of enrolled 150 medical students, a total of 82 reports were submitted during study period. After analyzing the reports, 6 were excluded due to duplication. It was found that most of the ADRs were related to skin and appendage disorders (30), gastrointestinal disorders (14) followed by adverse drug reactions related to nephrotoxicity, hepatotoxicity, thrombocytopenia, metabolic disorders, alopecia etc as shown in Table 1. Among the group of drugs, most commonly associated with adverse drug reactions were antibiotics, analgesics, and antiepileptics (Table 2).

Among antibiotics beta-lactams, quinolones were most commonly associated with ADRs followed by aminoglycosides and macrolides. Of analgesics which are second most common cause of ADRs among used drugs, diclofenac was most frequently associated with adverse reactions followed by ibuprofen, aspirin, and naproxen.

Table 1: Most frequently adverse drug reaction reported.

\begin{tabular}{|lll|}
\hline Adverse Drug reaction & Number & $\begin{array}{l}\text { Percentage } \\
(\%)\end{array}$ \\
\hline Rash & 23 & 30.2 \\
\hline Itching & 7 & 9.2 \\
\hline Vomiting & 9 & 11.8 \\
\hline Diarrhea & 5 & 6.5 \\
\hline Kidney disorders & 5 & 6.5 \\
\hline Blood disorders & 4 & 5.2 \\
\hline Liver Disorders & 3 & 3.9 \\
\hline Hyperglycemia & 3 & 3.9 \\
\hline Hyperkalemia & 3 & 3.9 \\
\hline Alopecia & 3 & 3.9 \\
\hline Headache & 2 & 2.6 \\
\hline Hypokalemia & 2 & 2.6 \\
\hline Mucositis & 2 & 2.6 \\
\hline Oral thrush & 1 & 1.31 \\
\hline Edema & 1 & 1.31 \\
\hline
\end{tabular}

Table 2: Most frequently suspected drugs reported.

\begin{tabular}{|lll|}
\hline Drug class & Number & Percentage (\%) \\
\hline Antibiotics & 28 & 36.8 \\
\hline Analgesics & 15 & 19.7 \\
\hline Anti-epileptics & 11 & 14.4 \\
\hline Diuretics & 6 & 7.8 \\
\hline Antihypertensive & 5 & 6.5 \\
\hline Hypoglycemics & 5 & 6.5 \\
\hline Anticancer & 3 & 3.9 \\
\hline Miscellaneous & 3 & 3.9 \\
\hline
\end{tabular}

Among antiepileptics, the sequential order of ADRs was phenytoin followed by carbamazepine, oxcarbazapine, valproic acid and lamotrigine (Table 3).

As per the WHO, UMC (Uppsala Monitoring Centre, Sweden) ADR reporting scale, the reports included adverse drug reactions in probable and possible classification (Table 4).

\section{DISCUSSION}

The present study was done as a part of sensitization and evaluation of $2^{\text {nd }}$ professional under graduate medical students who are future doctors and health care professionals in our society regarding, reporting of adverse drug reactions. Reporting ADRs is an essential component of Pharmacovigilance programme of India. Pharmacovigilance is an integral and essential part of patient care and the most important outcome of the programme is the prevention of patients being affected unnecessarily by negative consequences of 
pharmacotherapy. ${ }^{8}$ Health care system relies mainly on the detection and reporting of the suspected ADR to identify new reactions, record the frequency with which they are reported, evaluate factors that may increase risk and provide information to prescribers with a view to prevent future ADRs. With this aim National Pharmacovigilance Programme has been launched in India. ${ }^{9}$

Table 3: Most frequently involved antibiotic, analgesic and antiepileptic.

\begin{tabular}{|llll|}
\hline Group & & No. & (\%) \\
\hline \multirow{5}{*}{ Antibiotics } & Beta lactams & 9 & 32.14 \\
\cline { 2 - 4 } & Quinolones & 6 & 21.42 \\
\cline { 2 - 4 } & Aminoglycosides & 3 & 10.71 \\
\cline { 2 - 4 } & Macrolides & 3 & 10.71 \\
\cline { 2 - 4 } & Antitubercular & 3 & 10.71 \\
\cline { 2 - 4 } & Antivirals (non- & 2 & 7.14 \\
& retroviral) & 2 & 7.14 \\
\cline { 2 - 4 } Analgesics & Metronidazole & 2 & 40.0 \\
\hline & Diclofenac & 6 & 13.33 \\
\cline { 2 - 4 } & Paracetamol & 2 & 13.33 \\
\cline { 2 - 4 } & Ibuprofen & 2 & 13.33 \\
\cline { 2 - 4 } & Aspirin & 2 & 13.33 \\
\cline { 2 - 4 } Anti- & Naproxen & 1 & 6.66 \\
\cline { 2 - 4 } epileptics & Etorocoxib & 4 & 36.36 \\
\hline & Phenytoin & 2 & 18.18 \\
\cline { 2 - 4 } & Carbamazepine & 2 & 18.18 \\
\cline { 2 - 4 } & Oxcarbazapine & 1 & 9.9 \\
\cline { 2 - 4 } & Valproic acid & & \\
\cline { 2 - 4 } & Lamotrigine & 2.18 \\
\hline
\end{tabular}

Table 4: Characteristic of reports.

\begin{tabular}{|lll|}
\hline Causality assessment & Number & Percentage (\%) \\
\hline Certain & 0 & 0 \\
\hline Probable & 43 & 56.57 \\
\hline Possible & 33 & 43.43 \\
\hline Unlikely & 0 & 0 \\
\hline
\end{tabular}

According to Muraraiah $\mathrm{S}$ et al, the reasons for not reporting an ADR where mainly lack of facilities (50\%), followed by the belief that ADR in question is well known $(33 \%)$, lack of knowledge (12\%) and lack of time $(6 \%)$. Though the teaching faculty felt that the facilities for reporting ADRs need to be improved, the students were in doubt that whether the ADR to be reported was well known. This indicates that the students may need more training about what needs to be reported to the ADR centre. ${ }^{10}$ Also a study by Rehan et al, which was conducted at the Lady-Harding Medical College, New Delhi showed that the knowledge, attitude and the practice of both the undergraduates and the prescribers were comparable but they need further improvement. ${ }^{8}$

In present study, systems most commonly affected were dermatological in $39.4 \%$ of patients and gastrointestinal in $18.3 \%$ patients. The results are comparable with earlier
Indian spontaneous reporting studies which show both gastrointestinal and cutaneous reactions as predominantly affected systems. ${ }^{11-15}$ The drug class mostly associated with ADR was antibiotics in $36.8 \%$ of cases followed by non steroidal anti-inflammatory drugs in $19.7 \%$, antiepileptics in $14.4 \%$ in the present study. The results were consistent with an ADR reporting programme developed and implemented by Murphy and Frigo in Loyola University Medical Centre, a 563- bedded tertiary care teaching hospital located in the western suburbs of Chicago which revealed that the most common adverse reactions were rash and antibiotics were the most commonly implicated drug class. ${ }^{16}$ The anti-infective agents were also most frequently reporting offending drug class in earlier Indian spontaneous reporting studies. ${ }^{12,13,15}$ The students also satisfactorily documented demographics, onset date, duration, routes, indication to use, suspected drugs, their starting and stoppage along with de-challenge and rechallenge information. All the reported ADRs were probable and possible as per WHO-UMC classification.

\section{CONCLUSION}

This study strongly suggests that there is a greater need for streamlining of the hospital based ADR reporting and monitoring system to create awareness and to promote the reporting of ADRs among undergraduate medical and paramedical students. Lack of motivation and training towards ADR reporting and Pharmacovigilance discourages them from reporting. In that context, the present academic curriculum should be re structured with respect to Pharmacovigilance study so that there is adequate sensitization regarding reporting of ADRs as a part of the undergraduate training, internship and postgraduate training. Also regular CME's and workshops for all levels of health care system at institutional level and in private sector should be conducted. Lastly mass media including social media can be brought into use to spread the awareness about ADRs for contributing optimally to well-being of the society.

\section{ACKNOWLEDGEMENTS}

Authors would like to thank to the medical students who participated in the study.

\section{Funding: No funding sources \\ Conflict of interest: None declared \\ Ethical approval: Not required}

\section{REFERENCES}

1. A report of WHO meeting, WHO technical report, International Drug Monotoring; The role of National centres, Ser. 1972;498;1-25.

2. Desai C, Iyer G, Panchal J, Shah S, Dikshit R. An evaluation of knowledge, attitude, and practice of adverse drug reaction reporting among prescribers at a tertiary care hospital. Perspectives Clin Res. 2011;2(4):129-36. 
3. Medicine Io. To Err Is Human: Building a Safer Health System. Washington, DC: The National Academies Press; 2000.

4. Carrasco-Garrido P, de Andrés LA, Barrera VH, de Miguel GÁ, Jiménez-García R. Trends of adverse drug reactions related-hospitalizations in Spain (20012006). BMC Health Services Res. 2010;10(1):287.

5. Herdeiro MT, Figueiras A, Polónia J, Gestal-Otero JJ. Physicians' Attitudes and Adverse Drug Reaction Reporting. Drug Saf. 2005;28(9):825-33.

6. Eland, Belton, Grootheest V, et al. Attitudinal survey of voluntary reporting of adverse drug reactions. Br J Clin Pharmacol. 1999;48(4):623-7.

7. Gupta SK, Nayak RP, Shivaranjani R, Vidyarthi SK. A questionnaire study on the knowledge, attitude, and the practice of pharmacovigilance among the healthcare professionals in a teaching hospital in South India. Perspectives Clin Res. 2015; 6(1):45-52.

8. Rehan HS, Vasudev K, Tripathi CD. Adverse drug reaction monitoring: knowledge, attitude and practices of medical students and prescribers. Natl Med J India. 2002;15(1): 24-6.

9. Gaikwad NR, Yadav SS, Patil AB, Manjrekar PV, Jha RK. Awareness about adverse drug reactions monitoring among prescribers of rural teaching hospital of central India. JDMIMSU. 2009;4(3):173-6.

10. Muraraiah S, Rajarathna K, Sreedhar D, Basavalingu D, Jayanthi CR. A questionnaire study to assess the knowledge, attitude and practice of Pharmacovigilance in a paediatric tertiary care centre. J Chem Pharm Res. 2011;3(6):416-22.

11. Ramesh M, Pandit J, Parthasarathi G. Adverse drug reactions in a south Indian hospital-their severity and cost involved. Pharmacoepidemiol Drug Saf. 2003 Dec;12(8):687-92.

12. Rao PG, Archana B, Jose J. Implementation and results of an adverse drug reaction reporting programme at an Indian teaching hospital. Indian J Pharmacol. 2006 Jul 1;38(4):293-4.

13. Arulmani R, Rajendran SD, Suresh B. Adverse drug reaction monitoring in a secondary care hospital in South India. Br J Clin Pharmacol. 2008 Feb 1;65(2):210-6.

14. Jose J, Rao PGM. Pattern of adverse drug reactions notified by spontaneous reporting in an Indian tertiary care teaching hospital. Pharmacol Res. 2006;54(3):226-33.

15. Uppal R, Jhaj R, Malhotra S, India NM. Adverse drug reactions among inpatients in a north Indian referral hospital. Nat Med J f India. 2000 Jan 1;13(1):16-8.

16. Murphy BM, Frigo LC. Development, implementation, and results of a successful multidisciplinary adverse drug reaction reporting program in a university teaching hospital. Hospital Pharmacy. 1993 Dec; 28(12):1199-204.

Cite this article as: Bali ZS, Bhat MY, Farhat S, Nabi U. An evaluation of pattern of adverse drug reactions reporting by undergraduate medical students in a tertiary care hospital. Int $\mathrm{J}$ Basic Clin Pharmacol 2019;8:685-8. 